\section{Controlled drug use}

Concepts in Biochemical Pharmacology, Part 3. Edited by J. R. Gillette and J. R. Mitchell. (Handbook of Experimental Pharmacology, New Series, Vol. 28/3.) Pp. xxviii +480 . (Springer: Berlin and New York, 1975.) DM 198; $\$ 81.40$.

MANY powerful drugs are now available and if they are to be used to best effect we need knowledge not only of how they act on the body, but also of how the body deals with the drug; both aspects are equally important in deciding how we use the drug. Important questions are: how much do we give? When? How? And to whom? This book is concerned with answering those questions. Work in this important branch of pharmacology has greatly expanded in the past decade, and although several texts have been published none are quite as detailed, or complete, as the volume of which this book constitutes the final part. In contrast to the two earlier parts, which were concerned more with methodology and general principles, this deals in detail with practical applications. Throughout, the editors have sought contributions from experts who have generally succeeded in combining the basic concepts with considerations of

\section{Textbook of psychopharmacology}

Psychopharmacology: a Biological approach. (Series in Experimental Psychology.) By Robert. A Levitt. Pp. $x+502$. (Hemisphere: Washington, June 1975. Distributed by Halsted Press.) £9.45.

THE world still needs honest jobbing textbooks, and it is within that genre that the present volume takes its place. In the introduction, Professor Levitt describes the origins of this text as being material he prepared for a graduate seminar: seven of his students became sufficiently enthused subsequently to help in the further development of certain chapters, and they now appear as authors or coauthors. The result of this admirably cooperative venture is a text which is business-like and straightforward, but at the same time has about it a special feeling of enthusiasm. One may suspect that in this particular set of seminars no-one fell asleep.

The reasonable demands of any textbook should be that the facts are right, that the essential matters under treatment are adequately covered, and that the presentation is lucid. This book largely meets these basic expec- their clinical implications.

The first two chapters deal rigorously but comprehensibly with the mathematics of drug disposition. The second in particular relates the various models which have been developed to what actually happens in the body, with a full discussion of the importance of regional blood flow and protein binding. Subsequent chapters analyse factors which lead to individual variation in drug disposition (age, disease and genetic factors) and to variation within an individual (the route of drug administration and the form in which the drug is given). A section on drug interactions starts with a clear discussion of possible mechanisms and includes two interesting chapters which cover areas where beneficial interactions may occur: cancer and antimicrobial chemotherapy. The disadvantages of using antibiotics in combination are also stressed. A final section deals with some aspects of drug toxicity, particularly the role of chemically reactive drug metabolites in causing tissue damage.

The book achieves the same high standards of both content and presentation as its companion parts and together they constitute a most valuable reference work. Its detailed and rigorous approach make it most suited to clinical pharmacologists and

tations. The additional problem which an undergraduate text on psychopharmacology has then particularly to meet is the decision as to where the subject shall be circumscribed: neurophysiology, neuroanatomy, learning theory, clinical psychiatry, endocrinology, are among the obvious neighbouring states. In these borderlands it is difficult to find the balance between offering too much or too little contextual explanation and discussion, and in this regard the present text is not altogether successful. It is in these border areas that the student may be lost or mislead. For instance, in respectable circles amphetamines are not these days prescribed for treatment of depression. Involutional depression is not a synonym for endogenous depression. More importantly, there is an invitation to sad unawareness in the declaration that "Our position is that mental (behavioural) disorders are the sole result of either learning or physiological dysfunction, or some combination of the two". Indeed, in one section a "simplistic overview" is boldly offered as a good thing.

This is in many ways an attractive book, but that lively seminar material has not been entirely successfully transmuted into a rounded textbook of psychopharmacology.

Griffith Edwards research workers, particularly those involved in drug development. At the same time, a lot of what it has to say could be directly translated into prescribing practice, and it is to be hoped that it will reach a much wider readership among the medical profession.

D. G. Haylett

\section{Action of antitumour agents}

Antineoplastic and Immunosuppressive Agents. Part 1 and 2. (Handbook of Experimental Pharmacology, New Series. Vol. 38/1 and 2.) Edited by Alan C. Sartorelli and David G. Johns. Vol. 1, Pp. xxiv+762; DM258; \$105.30. Vol. 2, Pp. xxxii+1067; DM 278; \$119.80. (Springer: Berlin and New York, 1975.)

THIS two-volume book comprises a series of reviews, 79 in all, which give as wide a coverage of the nature of antitumour agents and their action as has yet been seen in one work

The general title might suggest that antineoplastic agents and immunosuppressive agents are different groups, whereas the latter are in practice drawn from the former. Only three chapters (Part I) are devoted specifically to immunosuppressive agents but the coverage is adequate; moreover, the immunological properties of agents are discussed in subsections in other chapters.

Part I contains the more general articles. It includes chapters on the rationale of drug design, the choice and use of agents, and drug resistance. The editors have also wisely included reviews on related topics: cell kinetics, cell growth regulation, radiation, immunotherapy, and pharmacology in the broadest sense (organism to molecule). Part II is devoted to a detailed treatment of various agents including hormones.

The team of well-known contributors assembled by the editors virtually ensured an authoritative compendium, packed with information, marked by a lack of uniformity in chapter organisation which should worry none but the perfectionist. Most of the contributions were probably written three or four years ago but a time lag is unavoidable in the preparation of such a work. New agents of real value do not emerge very often. It is therefore certain that those concerned with the fundamental aspects of drug action will find this handbook a valuable reference work for years to come. It is equally certain that the high price will almost totally exclude this meritorious work from private bookshelves.

J. A. Stock 